\title{
Slurry-phase hydrocracking of heavy oil and model reactant: effect of dispersed Mo catalyst
}

\author{
Hui Du $\cdot$ Ming Li $\cdot$ Dong Liu $\cdot$ Yuyang Ren $\cdot$ \\ Yajing Duan
}

Received: 11 June 2014/ Accepted: 16 November 2014/Published online: 10 January 2015

(C) The Author(s) 2014. This article is published with open access at Springerlink.com

\begin{abstract}
Thermal hydrocracking and catalytic hydrocracking of heavy oil and model reactant have been carried out to investigate the effect of dispersed Mo catalyst on slurry-phase hydrocracking. The XRD and XPS patterns suggested that the major existence form of dispersed Mo catalyst in slurry-phase hydrocracking was $\mathrm{MoS}_{2}$. Experimental data revealed that the conversion of feedstock oils and model reactant increased with the presence of catalyst, while the yields of light products (gas, naphtha) and heavy products (vacuum residue, coke) decreased, the yields of diesel and vacuum gas oil increased in the meantime. Besides, the yields of aromatic hydrocarbon and naphthenic hydrocarbon in naphtha fraction decreased. Effect parameters $R_{\mathrm{G}}$ (the ratio of $i-\mathrm{C}_{4} \mathrm{H}_{10}$ yield to $n-\mathrm{C}_{4} \mathrm{H}_{10}$ yield) and isoparaffin $/ n$-paraffin ratio were proposed to study the reaction mechanism of slurry-phase hydrocracking, the smaller effect parameters showed that there was no carbonium ion mechanism in slurry-phase hydrocracking, which still followed the free radical mechanism, and that the isomerization ratio of products decreased with the presence of Mo catalyst.
\end{abstract}

Keywords Slurry phase $\cdot$ Hydrocracking $\cdot$ Heavy oil · $\mathrm{MoS}_{2} \cdot$ Free radical mechanism $\cdot$ Molybdenum naphthenate

\section{Introduction}

The hydroprocessing of residue includes fixed bed, moving bed, ebullated bed and slurry-phase hydroprocessing

H. Du · M. Li · D. Liu ( ()$)$ Y. Ren · Y. Duan

State Key Laboratory of Heavy Oil Processing, China University of Petroleum, Qingdao 266555, People's Republic of China e-mail: 1dongupc@vip.sina.com technology. The slurry-phase hydrocracking is a promising technology, which could process inferior feedstock oils with the characteristics of high metal content, high sulphur content and high carbon residue, etc., [1-6].

Catalyst plays a significant role in slurry-phase hydrocracking, a catalyst with high activity will result in high yield of light fuel oil and low yield of coke. There are two kinds of catalyst for slurry-phase hydrocracking, heterogeneous solid powder catalysts and homogeneously dispersed catalysts [7]. However, the former, such as hematite, lignite coke and red mud [8-11], was no longer used because of the difficulty in separation and equipment wear caused by the high dosage [12]. Up to now, many homogeneously dispersed catalysts have been studied and developed, which could be formulated as water-soluble catalysts [13-16] and oil-soluble catalysts [17-21]. Homogeneously dispersed catalysts are metal compounds, and the metal is selected from elements of group IV B-VIII among which the molybdenum, nickel, cobalt and chromium are commonly used [22-25]. The homogeneously dispersed catalyst and feedstock oil were added into the reactor simultaneously, the catalyst was actually a precursor which could be converted to the active metal sulfides through a sulfuration reaction. Many molybdenum compounds were used as homogeneously dispersed catalysts in slurry-phase hydrocracking due to the high hydrogenation activity of $\mathrm{MoS}_{2}$ [26-29].

However, there is less research on the effect of dispersed Mo catalyst on slurry-phase hydrocracking, and a unified viewpoint which could be accepted by all researchers has not formed until now. Zhang et al. [30] reported the effect of dispersed catalyst in slurry-phase hydrocracking was to promote the conversion of feedstock oil and inhibit the formation of coke. Tops $\phi e$ [31, 32] proposed that the $-\mathrm{SH}$ groups on the $\mathrm{MoS}_{2}$ catalyst surface, which were created 
by heterolytic cleavage of hydrogen, possess the character of Bronsted acid when temperature was above $673 \mathrm{~K}$, thus, the carbonium ion mechanism was introduced into slurryphase hydrocracking process.

It is well known that slurry-phase hydrocracking is a catalytic hydrocracking process. Therefore, we discuss the difference of products composition and distribution between thermal and catalytic hydrocracking. Two effect parameters, $R_{\mathrm{G}}$ and isoparaffin $/ n$-paraffin ratio (naphtha fraction), were introduced to investigate the effect of dispersed Mo catalyst on slurry-phase hydrocracking. A larger value of effect parameters indicate that the carbonium ion mechanism is introduced into slurry-phase hydrocracking. A smaller value of effect parameters indicate that the slurry-phase hydrocracking still follows the free radical mechanism, and that the formation of isomerization products is suppressed by the dispersed Mo catalyst.

\section{Experimental}

\section{Raw material}

Karamay vacuum gas oil (KLVGO), Karamay vacuum residue (KLVR) and Venezuelan atmospheric residue (V$\mathrm{AR})$ were taken as feedstock oils for thermal hydrocracking and catalytic hydrocracking. The composition and properties of feedstock oils are shown in Table 1. Molybdenum naphthenate with the molybdenum content of 6.95 wt $\%$ was a homemade oil-soluble dispersed catalyst which was synthesized according to the literatures [33, 34]. Molybdenum naphthenate was applied as the catalyst in slurry-phase hydrocracking of feedstock oils; meanwhile, the sublimate sulfur powder (purity of $99.95 \%$, particle size $\leq 100 \mu \mathrm{m}$ ) was taken as a sulfurizer [34]. In this study, $n$-butylbenzene ( $5 \mathrm{wt} \%$ ) dissolved in $n$-pentane was used as model reactant. $\mathrm{MoS}_{2}$ powder (purity of $99.5 \%$, particle size $\leq 2 \mu \mathrm{m}$ ) was applied as the catalyst in slurry-phase hydrocracking of model reactant to avoid the product interference coming from molybdenum naphthenate. Sublimate sulfur, $n$-butylbenzene and $\mathrm{MoS}_{2}$ powder were purchased from Aladdin Industrial Inc.

\section{Hydrocracking of feedstock oils}

Thermal hydrocracking and catalytic hydrocracking reaction of feedstock oils $(200 \pm 5 \mathrm{~g})$ were carried out using a $500 \mathrm{ml}$ batch-type autoclave fitted with an electromagnetic stirrer. For catalytic hydrocracking reaction, $300 \mu \mathrm{g} \cdot \mathrm{g}^{-1}$ of molybdenum naphthenate (calculated by the molybdenum content) and $500 \mu \mathrm{g} \cdot \mathrm{g}^{-1}$ of sublimate sulfur were loaded into the autoclave. Therefore, the active molybdenum sulfide was formed during the catalytic hydrocracking reaction. Besides, other reaction conditions of the two reactions were common. The autoclave was charged with hydrogen to 8.0 MPa under room temperature, and then heated to $420{ }^{\circ} \mathrm{C}$ under the stirring of $500 \mathrm{rpm}$. After $1.0 \mathrm{~h}$, the autoclave was cooled to room temperature with water to cease the reaction. The gas products were released to the air through an alkali wash bottle. The autoclave contents were distilled to obtain the naphtha $\left(<180^{\circ} \mathrm{C}\right)$, diesel $\left(180-350{ }^{\circ} \mathrm{C}\right)$, vacuum gas oil (VGO $\left.350-500{ }^{\circ} \mathrm{C}\right)$ and distilled bottom $\left(>500{ }^{\circ} \mathrm{C}\right)$. Vacuum residue (VR) was the toluene-soluble fraction of distilled bottom, and the toluene-insoluble fraction was coke and sulfurized dispersed catalyst. The yields of product were calculated by the following equations:

Yield of product $(w t \%)=\frac{\text { product weight }}{\text { feedstock oil weight }} \times 100$

Yield of gas (wt $\%)$

$=\frac{\text { feedstock oil weight }- \text { autoclave contents weight }}{\text { feedstock oil weight }} \times 100$

The composition of gaseous product was measured using a CP3800 gas chromatography (Varian Inc.). The paraffin,

Table 1 Composition and properties of feedstock oils

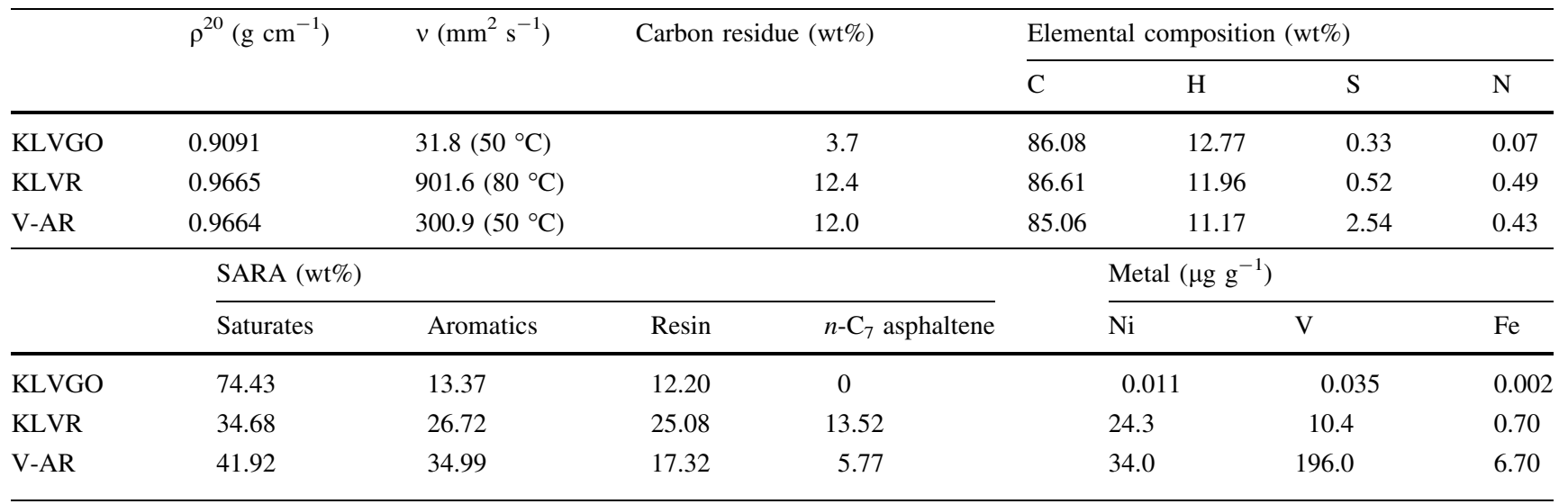


olefin, naphthenic hydrocarbon and aromatic hydrocarbon contents (PIONA) of naphtha fraction were defined by an Agilent gasoline PIONA composition analysis system. A Bruker Avance DMX500-type superconducting NMR spectrometer was used to determinate the ${ }^{1} \mathrm{H}$ nuclear magnetic resonance ( ${ }^{1} \mathrm{H}$ NMR) spectra of naphtha fraction.

\section{Characterization of dispersed catalyst}

Dispersed catalyst was separated from the VR product of KLVGO hydrocracking reaction by centrifuge with toluene used as the solvent. Then, the catalyst was dried in vacuum with the stream of nitrogen. The crystal structure of the dispersed catalyst was characterized by a PANalyitcal X Pert PRO MPD X-ray diffraction (XRD) with a $\mathrm{Cu} \mathrm{K} \alpha$ radiation $(l=0.15418 \mathrm{~nm})$. The X-ray photoelectron spectroscopy (XPS) spectra was recorded by a Kratos Axis Ultra DLD spectrometer employing a non-monochromatic $\mathrm{Mg} \mathrm{K} \alpha$ radiation $(\mathrm{h} v=1,253.6 \mathrm{eV})$.

\section{Hydrocracking of model reactant}

The hydrocracking of model reactant was investigated with the following conditions: initial hydrogen pressure, 2.0 Mpa; reaction temperature, $420{ }^{\circ} \mathrm{C}$; reaction time, $1.0 \mathrm{~h}$; stirring rate, $500 \mathrm{rpm}$; and $\mathrm{MoS}_{2}$ catalyst, $300 \mu \mathrm{g} \cdot \mathrm{g}^{-1}$ (calculated by the molybdenum content) only for catalytic hydrocracking reaction. The composition of gas product was examined quantitatively using a gas chromatography. An Agilent 7890A/5975C gas chromatography coupled with mass spectroscopy (GC-MS) was used to estimate the composition of liquid product.

\section{Results and discussion}

\section{Characterization of dispersed catalyst}

Figure 1 shows X-ray diffraction spectra of dispersed catalyst separated from the VR product of KLVGO hydrocracking reaction. The diffraction peaks at $2 \theta=15^{\circ}$ (003), $33^{\circ}-34^{\circ}(101)$ and $59^{\circ}$ (110) indicate that the crystallite of $\mathrm{MoS}_{2}$ exist. However, according to the standard XRD pattern of $\mathrm{MoS}_{2}$, the diffraction peaks of $\mathrm{MoS}_{2}$ are sharper than that of dispersed catalyst, which show that the crystallinity of dispersed catalyst is lower.

The XPS patterns of dispersed catalyst, indicate the $S_{2 p}$ and $\mathrm{Mo}_{3 \mathrm{~d}}$ peaks, are shown in Fig. 2, thus, the species of sulfide on catalyst are identified. From Fig. 2a, the peak at 162.0 and $168.4 \mathrm{eV}$ are ascribed to $\mathrm{S}^{2-}$ and $\mathrm{S}^{6+}$, respectively. Comparing the areas of two peaks, the result shows that the main existing form of $\mathrm{S}$ is $\mathrm{S}^{2-}$. It can be seen from Fig. $2 b$ that there is only one chemical environment for Mo in the dispersed catalyst, the peaks at 229.1 and $232.2 \mathrm{eV}$ are ascribed to $\mathrm{Mo}_{3 \mathrm{~d} 5 / 2}$ and $\mathrm{Mo}_{3 \mathrm{~d} 3 / 2}$, respectively. Taken together, the XRD and XPS patterns suggest that the dispersed catalyst exists mainly in the form of $\mathrm{MoS}_{2}$.

Hydrocracking of feedstock oils

The feedstock oils reacted with the following conditions: initial hydrogen pressure, $8.0 \mathrm{MPa}$; reaction temperature, $420{ }^{\circ} \mathrm{C}$; reaction time, $1 \mathrm{~h}$; stirring rate, $500 \mathrm{rmp}$, $300 \mu \mathrm{g} \cdot \mathrm{g}^{-1}$ of molybdenum naphthenate (calculated by the molybdenum content) and $500 \mu \mathrm{g} \cdot \mathrm{g}^{-1}$ of sublimate sulfur only for catalytic hydrocracking reaction.

Figure 3 shows that the presence of molybdenum naphthenate led to low yields of gas, naphtha, VR and coke. Under the hydrocracking conditions, the edge and corner sulfur ions in $\mathrm{MoS}_{2}$ can be readily removed, then the coordinatively unsaturated sites (CUS) and sulfur ion vacancies are formed. $\mathrm{H}_{2}$ molecule splits to hydrogen free radical through homolytic and heterolytic ways on the CUS [35]. The hydrogen free radical that subsequently transfers into feedstock oils mainly involves in the following reactions: hydrogen abstraction reaction with alkane; addition reaction with olefin and aromatic hydrocarbon; and combining with another free radical to form a stable molecule. The hydrocarbon free radical is mainly produced though the thermal cracking of hydrocarbon. Thus, the degree of
Fig. 1 XRD spectra of dispersed catalyst

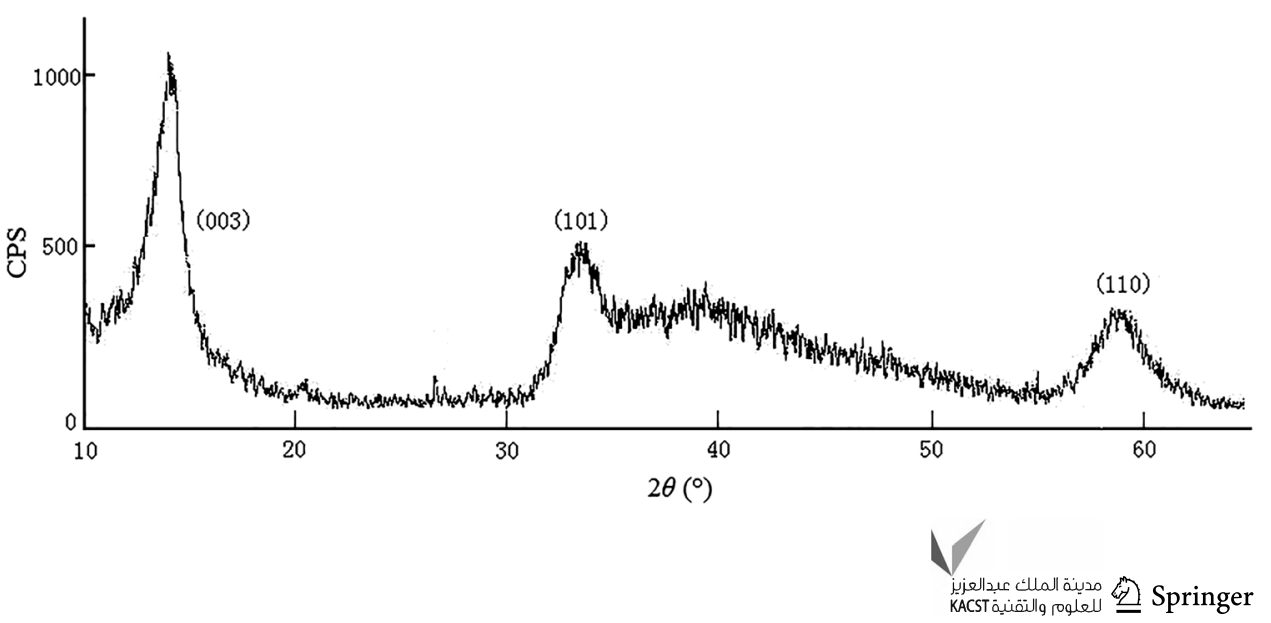


Fig. 2 XPS spectra of dispersed catalyst: a $\mathrm{S}_{2 \mathrm{p}}$ and b $\mathrm{Mo}_{3 \mathrm{~d}}$
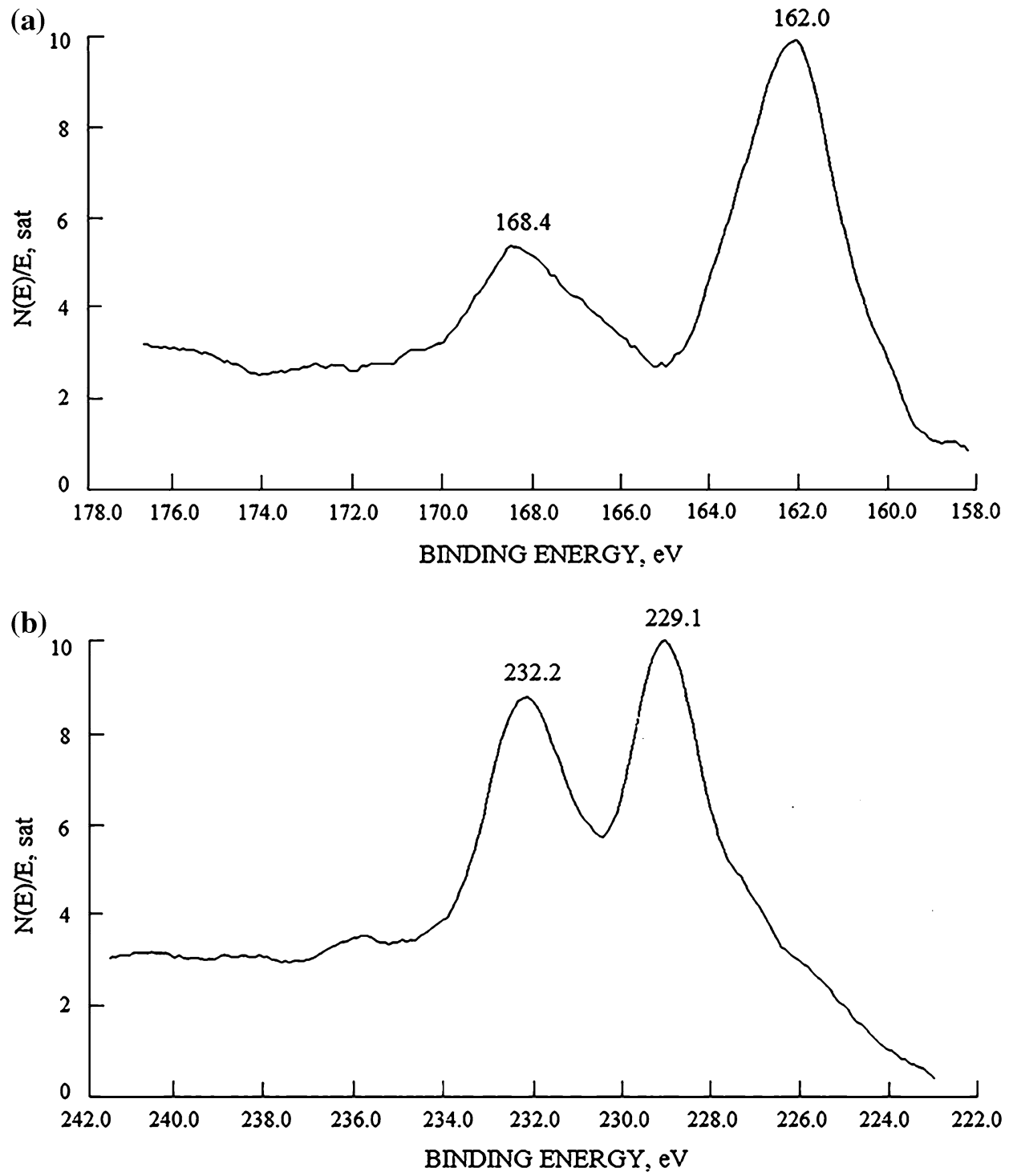

larger molecule cracking at thermal hydrocracking and catalytic hydrocracking would be the same under the same reaction temperature and time. With the presence of molybdenum naphthenate, the higher hydrogen free radical concentration promoted the combination of hydrogen free radical and hydrocarbon free radical. Therefore, the conversions of feedstock oils are increased with the presence of dispersed Mo catalyst. Meanwhile, the serious cracking and condensation of hydrocarbon free radical were suppressed, which reduced the yields of light products (gas, naphtha) and heavy products (VR, coke), respectively. Taken the KLVR experiments as example, the unreactive KLVR yield of catalytic hydrocracking was decreased from $23.67 \mathrm{wt} \%$ of thermal hydrocracking to $21.73 \mathrm{wt} \%$, which means that the conversion of KLVR was increased from 76.33 to $78.27 \mathrm{wt} \%$. Meanwhile, the coke yield was decreased from 6.53 to $5.23 \mathrm{wt} \%$. Therefore, the dispersed catalyst obviously increased the conversion of feedstock oils, meanwhile, the serious cracking and coke formation were inhibited.

It is known that thermal hydrocracking follows the free radical mechanism, the major components of gaseous product are $\mathrm{C}_{1}$ and $\mathrm{C}_{2}$, while that are $\mathrm{C}_{3}$ and $\mathrm{C}_{4}$ in catalytic cracking following the carbonium ion mechanism [36]. As shown in Table 2, the gaseous products of catalytic hydrocracking and thermal hydrocracking have the same composition. The paraffin yields were above 96 vol \% among which the yield of methane and ethane was 73-78 vol $\%$. Therefore, the presence of molybdenum naphthenate did not change the mechanism of slurry-phase hydrocracking, the $\mathrm{C}-\mathrm{C}$ bond cleavage still followed the free radical mechanism.

The oxygen contents of KLVGO, KLVR and V-AR were calculated by subtraction method according to the 


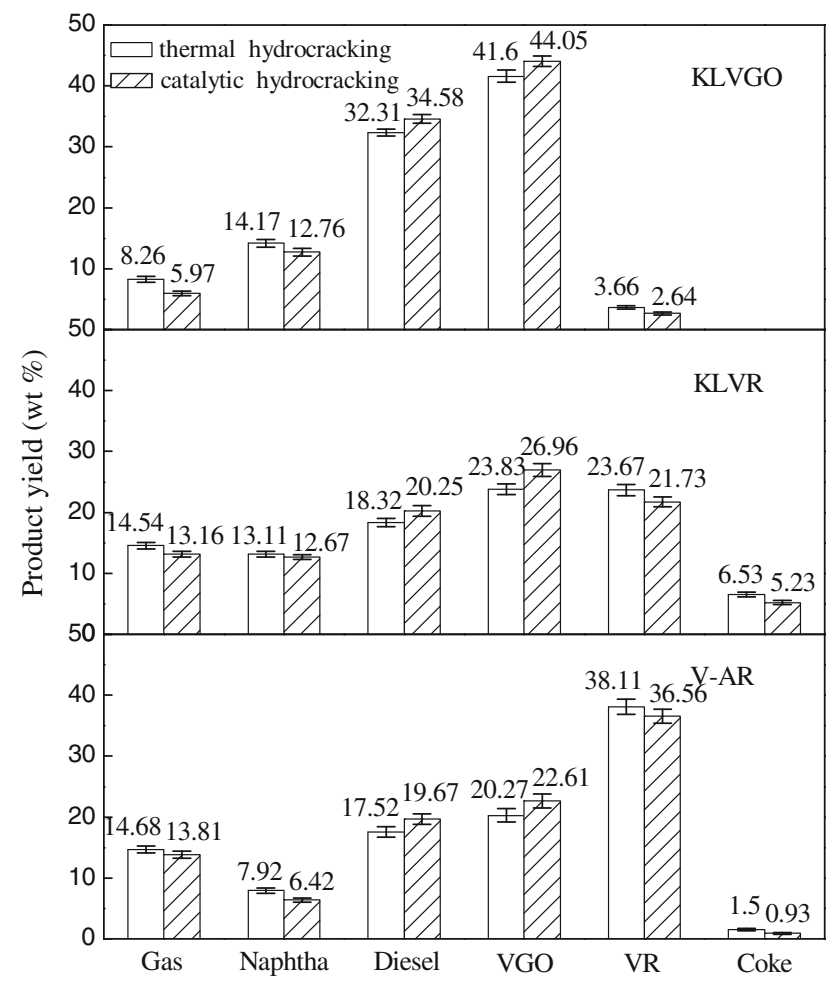

Fig. 3 Product yield of feedstock oils at thermal hydrocracking and catalytic hydrocracking

Table 2 Gaseous product distribution of feedstock oils at thermal hydrocracking and catalytic hydrocracking

\begin{tabular}{|c|c|c|c|c|c|c|}
\hline & \multicolumn{2}{|c|}{$\begin{array}{l}\text { Product yield of } \\
\text { KLVGO (vol \%) }\end{array}$} & \multicolumn{2}{|c|}{$\begin{array}{l}\text { Product yield of } \\
\text { KLVR (vol \%) }\end{array}$} & \multicolumn{2}{|c|}{$\begin{array}{l}\text { Product yield of } \\
\text { V-AR (vol \%) }\end{array}$} \\
\hline & $\mathrm{TH}^{\mathrm{a}}$ & $\mathrm{CH}^{\mathrm{b}}$ & $\mathrm{TH}$ & $\mathrm{CH}$ & $\mathrm{TH}$ & $\mathrm{CH}$ \\
\hline $\mathrm{CH}_{4}$ & 57.10 & 56.04 & 58.13 & 58.19 & 59.17 & 58.62 \\
\hline $\mathrm{C}_{2} \mathrm{H}_{6}$ & 18.04 & 17.78 & 18.80 & 18.66 & 17.99 & 17.90 \\
\hline $\mathrm{C}_{2} \mathrm{H}_{4}$ & 0.29 & 0.27 & 0.26 & 0.26 & 0.19 & 0.19 \\
\hline $\mathrm{C}_{3} \mathrm{H}_{8}$ & 13.37 & 13.51 & 13.51 & 13.35 & 13.45 & 13.61 \\
\hline $\mathrm{C}_{3} \mathrm{H}_{6}$ & 0.63 & 0.98 & 0.69 & 0.67 & 0.82 & 0.94 \\
\hline$i-\mathrm{C}_{4} \mathrm{H}_{10}$ & 1.86 & 1.82 & 2.32 & 2.25 & 1.92 & 1.85 \\
\hline$n-\mathrm{C}_{4} \mathrm{H}_{10}$ & 2.55 & 2.71 & 2.75 & 2.94 & 2.56 & 2.77 \\
\hline trans-2- $\mathrm{C}_{4} \mathrm{H}_{8}$ & 0.18 & 0.23 & 0.10 & 0.10 & 0.14 & 0.12 \\
\hline $1-\mathrm{C}_{4} \mathrm{H}_{8}$ & 0.20 & 0.27 & 0.12 & 0.12 & 0.13 & 0.13 \\
\hline cis-2- $\mathrm{C}_{4} \mathrm{H}_{8}$ & 0.15 & 0.10 & 0.15 & 0.14 & 0.13 & 0.11 \\
\hline$i-\mathrm{C}_{5} \mathrm{H}_{12}$ & 2.15 & 2.49 & 1.24 & 1.33 & 1.29 & 1.35 \\
\hline$n-\mathrm{C}_{5} \mathrm{H}_{12}$ & 1.82 & 2.21 & 0.78 & 0.85 & 0.87 & 0.91 \\
\hline cis-2- $\mathrm{C}_{5} \mathrm{H}_{10}$ & 0.03 & 0.04 & 0.20 & 0.16 & 0.14 & 0.18 \\
\hline $\mathrm{CO}$ & 1.14 & 1.13 & 0.56 & 0.62 & 0.76 & 0.81 \\
\hline $\mathrm{CO}_{2}$ & 0.45 & 0.37 & 0.33 & 0.32 & 0.41 & 0.45 \\
\hline $\mathrm{C}_{6+}$ & 0.04 & 0.05 & 0.06 & 0.04 & 0.03 & 0.06 \\
\hline
\end{tabular}

a Thermal hydrocracking

b Catalytic hydrocracking element composition in Table 1, which were $0.75,0.42$ and $0.57 \mathrm{wt} \%$, respectively. Total yields of $\mathrm{CO}$ and $\mathrm{CO}_{2}$ were determined by the oxygen contents of feedstock oils which followed the order of KLVGO $>$ V-AR $>$ KLVR as well as the order of oxygen content.

Although the presence of molybdenum naphthenate did not change the gaseous product composition of slurryphase hydrocracking, it did change the ratio of some products. Therefore, $R_{\mathrm{G}}$ (the ratio of $i-\mathrm{C}_{4} \mathrm{H}_{10}$ yield to $n-\mathrm{C}_{4} \mathrm{H}_{10}$ yield) was defined to explain the effect of molybdenum naphthenate on slurry-phase hydrocracking. The experimental result of KLVGO showed that, with the presence of molybdenum naphthenate, the $i-\mathrm{C}_{4} \mathrm{H}_{10}$ yield was decreased from 1.86 to 1.82 vol $\%$, while the $n-\mathrm{C}_{4} \mathrm{H}_{10}$ yield was increased from 2.55 to $2.71 \mathrm{vol} \%$, which indicated that the $R_{\mathrm{G}}$ value was decreased from 0.729 to 0.672 . Therefore, a larger value of $R_{\mathrm{G}}$ indicates that there are relatively more isomerization products in gaseous products. The thermal hydrocracking and catalytic hydrocracking gaseous products of feedstock oils were analyzed and the $R_{\mathrm{G}}$ values were calculated, as listed in Table 3.

For any kind of feedstock oil, the $R_{\mathrm{G}}$ value decreased when the reaction followed catalytic hydrocracking pathway, which indicated that there were relatively less isomerization products. During the catalytic hydrocracking process, the higher concentration of hydrogen free radical could inhibit the combination of two hydrocarbon free radicals, which generated the formation of isomerization products. Meanwhile, the hydrogen atom on tertiary carbon of isomerization product could easily be substituted by hydrogen free radical, which led to the cracking of isomerization products.

${ }^{1} \mathrm{H}$ NMR spectra of naphtha products from V-AR thermal hydrocracking and catalytic hydrocracking are shown in Figs. 4 and 5, respectively. In ${ }^{1} \mathrm{H}$ NMR spectra of naphtha fraction, the chemical shift $(\delta)$ in range of $0.5-1.0$ is ascribed to hydrogen atom of methyl group, while the $\delta$ in range of 1.0-3.5 is ascribed to hydrogen atom of methylene group and methenyl group. The intensities of various hydrogen atoms are calculated by integration of peak area. Branchiness index (BI) of naphtha fraction is calculated by the following equation:

Table 3 The $R_{\mathrm{G}}$ value of feedstock oils at thermal hydrocracking and catalytic hydrocracking

\begin{tabular}{|c|c|c|}
\hline & \multicolumn{2}{|l|}{$R_{\mathrm{G}}$} \\
\hline & Thermal hydrocracking & Catalytic hydrocracking \\
\hline KLVGO & 0.729 & 0.672 \\
\hline KLVR & 0.844 & 0.765 \\
\hline V-AR & 0.750 & 0.668 \\
\hline
\end{tabular}


Fig. $4{ }^{1} \mathrm{H}$ NMR of naphtha product from V-AR at thermal hydrocracking

Fig. $5{ }^{1} \mathrm{H}$ NMR of naphtha product from V-AR at catalytic hydrocracking
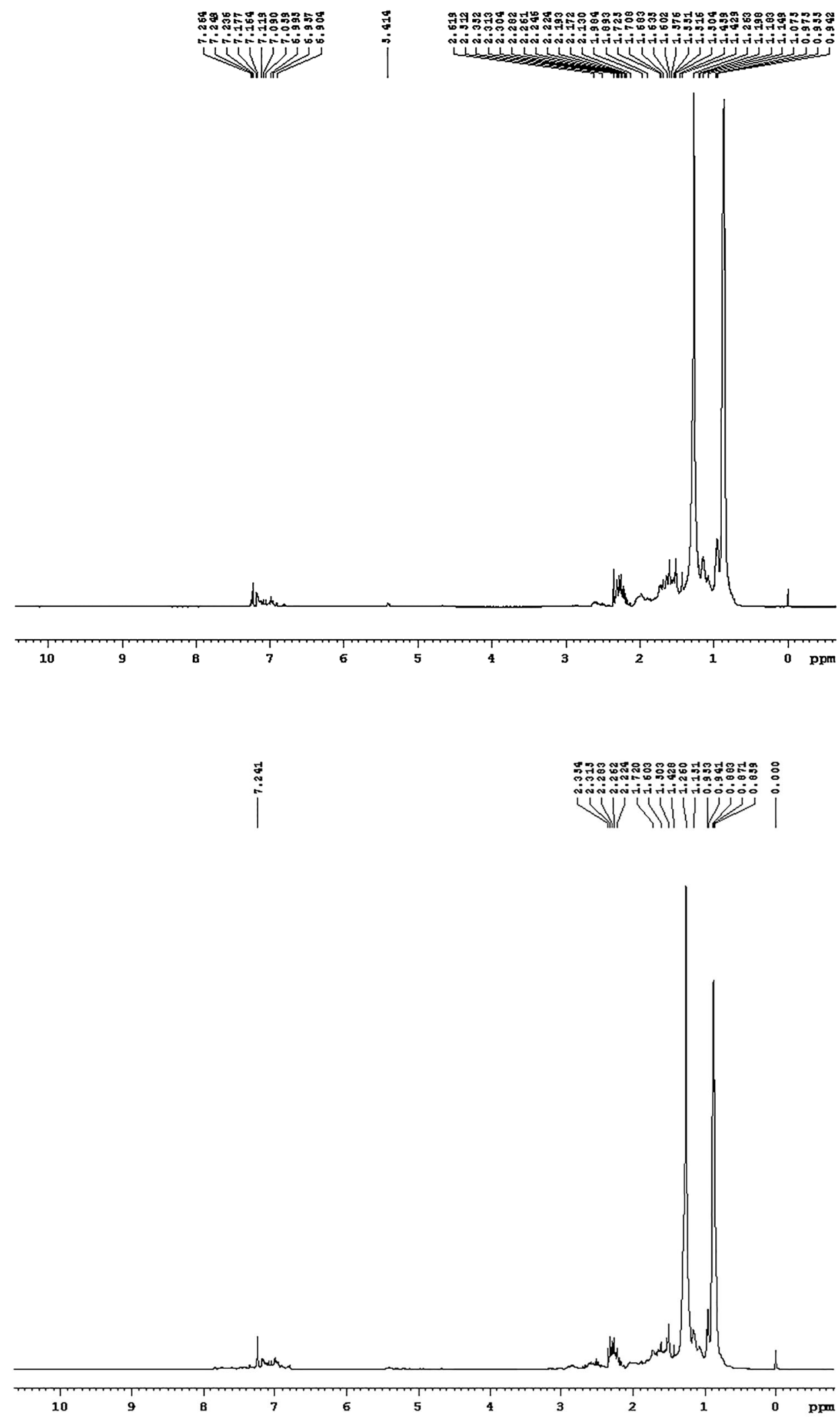
Table 4 The related integral areas of hydrogen atoms and BI of naphtha product from $\mathrm{V}-\mathrm{AR}$ at thermal hydrocracking and catalytic hydrocracking

\begin{tabular}{llll}
\hline & $\mathrm{S}_{\mathrm{CH} 3}$ & $\mathrm{~S}_{(\mathrm{CH} 2+\mathrm{CH})}$ & $\mathrm{BI}$ \\
\hline Thermal hydrocracking & 9.536 & 14.420 & 0.441 \\
Catalytic hydrocracking & 7.408 & 12.558 & 0.393 \\
\hline
\end{tabular}

$\mathrm{BI}=\frac{1 / 3 \mathrm{~S}_{\mathrm{CH}_{3}}}{1 / 2 \mathrm{~S}_{\left(\mathrm{CH}_{2}+\mathrm{CH}\right)}}$

The integration of various hydrogen atoms and BI of naphtha product from V-AR thermal hydrocracking and catalytic hydrocracking are listed in Table 4 . When V-AR reaction followed the thermal hydrocracking, the BI of naphtha fraction was 0.441 , which decreased to 0.393 with the presence of molybdenum naphthenate. The results revealed that the isomerization ratio of naphtha fraction was less when V-AR followed the catalytic hydrocracking process.

The further research on isomerization ratio of naphtha fraction was examined by a gasoline PIONA composition analysis system. Products distribution and the isoparaffin/ $n$-paraffin ratio of naphtha product from thermal hydrocracking and catalytic hydrocracking of feedstock oils are given in Table 5. The yields of naphthenic hydrocarbon and aromatic hydrocarbon decreased with presence of molybdenum naphthenate, while the yields of $n$-paraffin increased. Hydrogen molecule split to hydrogen free radical easily on the CUS of $\mathrm{MoS}_{2}$, which leads to the increase of hydrogen free radical concentration in reaction system. Thus, the probability of contact and reaction between naphthenic hydrocarbon, aromatic hydrocarbon and hydrogen free radical increased. The aromatic hydrocarbon converted to naphthenic hydrocarbon by hydrogenation saturation process at first, and then the naphthenic free radical formed because hydrogen atom was seized by hydrogen free radical which could be cracked to small molecule through free radical chain reaction pathway.

The isoparaffin $/ n$-paraffin ratio was calculated which could reflect the isomerization ratio of naphtha fraction. From Table 5, the naphtha fraction got a lower isoparaffin/ $n$-paraffin ratio when feedstock oil reaction followed the catalytic hydrocracking pathway. The same variation of isoparaffin $/ n$-paraffin ratio and BI proved that the catalytic hydrocracking reaction did not follow the carbonium ion mechanism and the formation of isoparaffin was suppressed by the catalyst.

In conclusion, the effect of dispersed Mo catalyst on residue slurry-phase hydrocracking can be explained using Fig. 6. More hydrogen free radicals are formed on the surface of dispersed Mo catalyst, which are easily combined with hydrocarbon free radicals. Thus, the serious cracking and condensation of macromolecular free radical is inhibited, and also the formation of isoparaffin. Furthermore, the conclusion is examined by the thermal and catalytic hydrocracking of model reactant.

\section{Hydrocracking of model reactant}

A mixed system of $n$-butylbenzene ( $5 \mathrm{wt} \%)$ and $n$-pentane (95 wt\%) was used as model reactant in this study. The model reactant reacted with the following conditions: initial hydrogen pressure, $2.0 \mathrm{MPa}$; reaction temperature, $420{ }^{\circ} \mathrm{C}$; reaction time, $1 \mathrm{~h}$; stirring rate, $500 \mathrm{rmp}$; and $\mathrm{MoS}_{2}$ catalyst, $300 \mathrm{ppm}$ only for catalytic hydrocracking. The model reactant could reach supercritical state under the reaction conditions. However, the $\mathrm{MoS}_{2}$ catalyst still had a good dispersion in reaction system due to the electromagnetic stirring. As the $95 \mathrm{wt} \%$ of model reactant was $n$ pentane, the $n$-pentane in gaseous product was removed to avoid the error effecting in data processing.

The gaseous product distributions of model reactant after thermal hydrocracking and catalytic hydrocracking are shown in Table 6. Methane and ethane were the major

Table 5 PIONA of naphtha product from feedstock oils at thermal hydrocracking and catalytic hydrocracking

\begin{tabular}{|c|c|c|c|c|c|c|}
\hline & \multicolumn{2}{|c|}{ Product yield of KLVGO (wt\%) } & \multicolumn{2}{|c|}{ Product yield of KLVR (wt\%) } & \multicolumn{2}{|c|}{ Product yield of V-AR (wt\%) } \\
\hline & $\mathrm{TH}^{\mathrm{a}}$ & $\mathrm{CH}^{\mathrm{b}}$ & $\mathrm{TH}$ & $\mathrm{CH}$ & $\mathrm{TH}$ & $\mathrm{CH}$ \\
\hline$n$-paraffin & $22.01 \pm 0.28$ & $25.56 \pm 0.36$ & $21.69 \pm 0.22$ & $24.88 \pm 0.26$ & $22.21 \pm 0.27$ & $25.18 \pm 0.31$ \\
\hline Isoparaffin & $32.92 \pm 0.36$ & $32.82 \pm 0.41$ & $32.45 \pm 0.32$ & $32.46 \pm 0.29$ & $35.12 \pm 0.39$ & $34.82 \pm 0.33$ \\
\hline Olefin & $10.36 \pm 0.14$ & $10.03 \pm 0.17$ & $10.61 \pm 0.21$ & $10.55 \pm 0.18$ & $10.95 \pm 0.15$ & $10.72 \pm 0.18$ \\
\hline Naphthenic hydrocarbon & $21.82 \pm 0.33$ & $20.55 \pm 0.28$ & $22.17 \pm 0.26$ & $20.66 \pm 0.22$ & $20.04 \pm 0.23$ & $19.62 \pm 0.19$ \\
\hline Aromatic hydrocarbon & $12.89 \pm 0.18$ & $11.04 \pm 0.21$ & $13.08 \pm 0.17$ & $11.45 \pm 0.25$ & $11.68 \pm 0.21$ & $9.66 \pm 0.15$ \\
\hline Isoparaffin/n-paraffin ratio & 1.496 & 1.284 & 1.496 & 1.305 & 1.581 & 1.383 \\
\hline
\end{tabular}

a Thermal hydrocracking

b Catalytic hydrocracking 
Fig. 6 Schematic diagram of the effect mechanism of Mo catalyst in residue slurry-phase hydrocracking

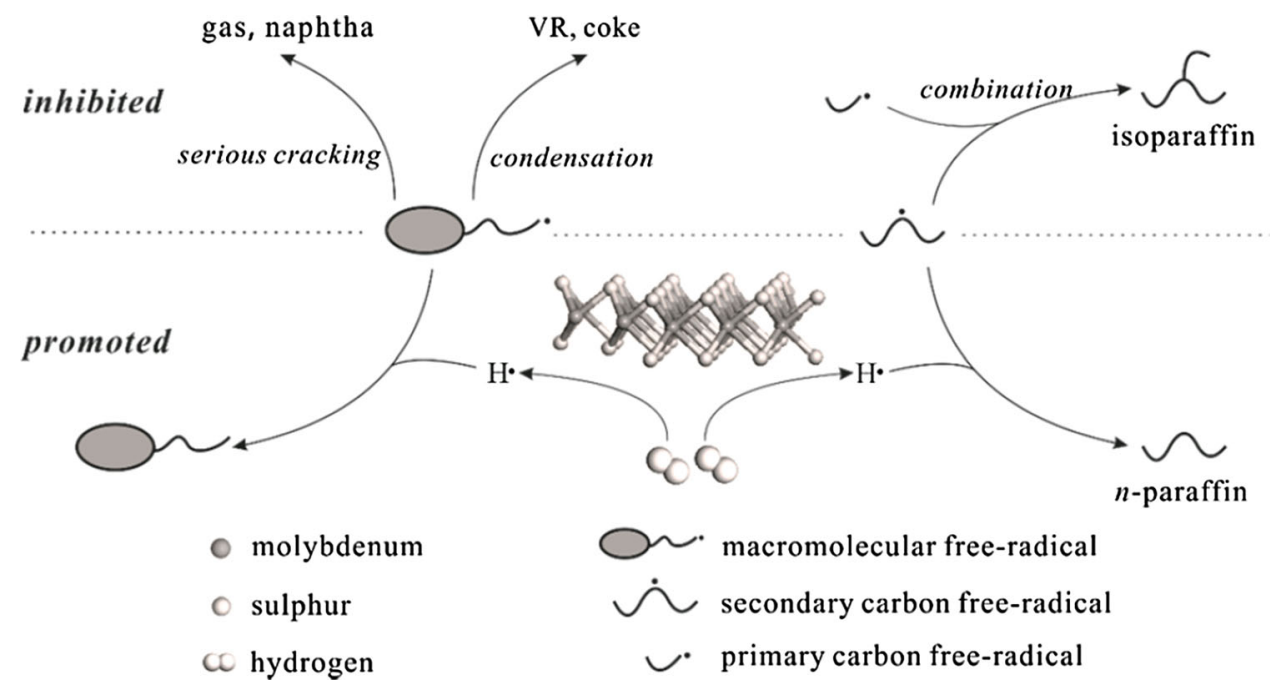

Table 6 Gaseous product distribution of model reactant at thermal hydrocracking and catalytic hydrocracking

\begin{tabular}{lll}
\hline & Product yield (vol \%) \\
\cline { 2 - 3 } & Thermal hydrocracking & Catalytic hydrocracking \\
\hline $\mathrm{CH}_{4}$ & 20.213 & 21.202 \\
$\mathrm{C}_{2} \mathrm{H}_{6}$ & 63.269 & 63.259 \\
$\mathrm{C}_{2} \mathrm{H}_{4}$ & 2.745 & 2.694 \\
$\mathrm{C}_{3} \mathrm{H}_{8}$ & 8.164 & 8.146 \\
$\mathrm{C}_{3} \mathrm{H}_{6}$ & 1.563 & 0.837 \\
$i-\mathrm{C}_{4} \mathrm{H}_{10}$ & 0.625 & 0.476 \\
$n-\mathrm{C}_{4} \mathrm{H}_{10}$ & 0.863 & 0.933 \\
trans $-2-\mathrm{C}_{4} \mathrm{H}_{8}$ & 0.172 & 0.183 \\
$1-\mathrm{C}_{4} \mathrm{H}_{8}$ & 1.456 & 1.312 \\
$i-\mathrm{C}_{4} \mathrm{H}_{8}$ & 0.462 & 0.502 \\
cis $-2-\mathrm{C}_{4} \mathrm{H}_{8}$ & 0.468 & 0.456 \\
\hline
\end{tabular}

components of gaseous product, while the olefin yield of catalytic hydrocracking gaseous product was decreased from 6.866 vol \% of thermal hydrocracking gaseous product to 5.984 vol $\%$. $R_{\mathrm{G}}$ values of model reactant that followed thermal hydrocracking and catalytic hydrocracking pathway were 0.724 and 0.510 , respectively. Compared to the $R_{\mathrm{G}}$ value of model reactant reacted without $\mathrm{MoS}_{2}$ catalyst, $R_{\mathrm{G}}$ value decreased by $29.6 \%$ when the reaction followed catalytic hydrocracking pathway. However, the $R_{\mathrm{G}}$ value decreased less than $10 \%$ when the reactant was feedstock oils. The bigger decrease of $R_{\mathrm{G}}$ value in model reactant experiments was caused by the sustainable activity of $\mathrm{MoS}_{2}$ catalyst. Nitrogen compounds and coke [37, 38], which could contribute to the catalyst deactivation during the heavy oil hydrocracking process, does not exist in the model reactant system. Therefore, hydrogen free radical was provided during the whole reaction process and the formation of isomerization products was suppressed sharply.

Liquid product distributions of model reactant after thermal hydrocracking and catalytic hydrocracking are shown in Table 7. $\mathrm{N}$-butylbenzene yields of liquid products from thermal hydrocracking and catalytic hydrocracking of model reactant were 76.93 and 74.17 wt\%, respectively. Thus, the model reactant has a higher conversion when the reaction followed catalytic hydrocracking pathway. Meanwhile, the yield of aromatic hydrocarbons was decreased from 13.95 to $6.41 \mathrm{wt} \%$, and the isomerization product yield was decreased from 7.76 to $5.62 \mathrm{wt} \%$. As shown in Table 7, 1.91 wt $\%$ of $n$ - heptylbenzene was produced in the thermal hydrocracking reaction, which was not found in the liquid products of catalytic hydrocracking reaction. The $n$-heptylbenzene produced by the combination of two hydrocarbon free radicals, which was suppressed by the higher concentration of hydrogen free radical in the catalytic hydrocracking reaction.

\section{Conclusion}

The results of this study indicate that the product composition of thermal hydrocracking and catalytic hydrocracking are the same; therefore, there is no carbonium ion mechanism in slurry-phase hydrocracking, which still follows the free radical mechanism. The conversion of feedstock oils and model reactant increased with the presence of Mo catalyst. The slurry-phase hydrocracking of heavy oil can suppress the unsatisfactory products (gas, VR, coke). $R_{\mathrm{G}}$ value, BI and PIONA results indicate that the higher concentration of hydrogen free radical created on the dispersed catalyst promotes the cracking of aromatic hydrocarbon and naphthenic hydrocarbon, however, the formation of isomerization products is suppressed. 
Table 7 Liquid product distribution of model reactant at thermal hydrocracking and catalytic hydrocracking

Product yield (wt \%)
$\begin{aligned} & \text { Thermal } \\ & \text { hydrocracking }\end{aligned}$ $\begin{aligned} & \begin{array}{l}\text { Catalytic } \\ \text { hydrocracking }\end{array} \\ & 0.40\end{aligned}$

Acknowledgments The authors gratefully acknowledge financial support from the National Natural Science Foundation of China (21176259).

Open Access This article is distributed under the terms of the Creative Commons Attribution License which permits any use, distribution, and reproduction in any medium, provided the original author(s) and the source are credited.

\section{References}

1. Rana MS, Sámano V, Ancheyta J, Diaz JAI (2007) A review of recent advances on process technologies for upgrading of heavy oils and residua. Fuel 86:1216-1231

2. Speight JG (2004) New approaches to hydroprocessing. Catal Today 98(1-2):55-60
3. Zhang SY, Liu D, Deng WA, Que GH (2007) A review of slurryphase hydrocracking heavy oil technology. Energy Fuels 21(6):3057-3062

4. Sugimoto Y (2006) Slurry phase hydrocracking of heavy oil over Ni-Mo/carbon catalyst. In: 16th Saudi Arabia-Japan Joint Symposium. Dhahran, Saudi Arabia

5. Bianco AD, Panariti N, Carlo SD, Beltrame PL, Carniti P (1994) New developments in deep hydroconversion of heavy oil residues with dispersed catalysts. 2. Kinetic aspects of reaction. Energy Fuels 8(3):593-597

6. Martinez-Grimaldo HJ, Chavarria-Hernandez JC, Ramirez J, Cuevas R, Ortiz-Moreno H (2011) Prediction of sulfur content, API gravity, and viscosity using a continuous mixture kinetic model for Maya crude oil hydrocracking in a slurry-phase reactor. Energy Fuels 25:3605-3614

7. Khulbe CP, Belinko K, Waugh RJ, Perreault M (1990) Process for preparing an iron-coal slurry catalyst for hydrocracking heavy oils. US Patent 4,923,838

8. Matsumura A, Sato S, Kondo T, Saito I, Souza WF (2005) Hydrocracking Marlim vacuum residue with natural limonite. Part 2: experimental cracking in a slurry-type continuous reactor. Fuel 84(4):417-421

9. Rupp M, Spencer R, Cook B (2010) Slurry phase residue hydrocracking-a superior technology to maximize liquid yield and conversion from residue \& extra heavy oil. In: NPRA Annual Meeting. Phoenix

10. Huy CN, Kweon H, Kim H, Kim DK, Kim DW, Oh SH, Shin EW (2012) Slurry-phase hydrocracking of vacuum residue with a disposable red mud catalyst. Appl Catal A Gen 447-448:186-192

11. Huy CN, Kweon H, Kim DK, Kim DW, Oh SH, Shin EW (2013) Modification of disposable red-mud catalysts for slurry-phase hydrocracking of vacuum residue. Chem Eng Technol 36(8):1365-1370

12. Noguera G, Araujo S, Hernández J, Rivas A, Mendoza D, Castellano O (2012) A comparative activity study of a new ultradispersed catalyst system for a hydrocracking/hydrotreating technology using vacuum residue oil: Merey/Mesa. Chem Eng Res Des 90:1979-1988

13. Guan CS, Wang ZX, Guo AJ, Que GH (2003) Study on slurry catalyst for kelamayi residue hydrocracking. J Fuel Chem Technol 31(5):434-438

14. Guan CS, Wang ZX, Guo AJ, Que GH (2004) Sulfurization of water-soluble catalyst for suspended bed hydrocracking of residue. Acta Petrol Sin (Petrol Process) 20(2):75-80

15. Liu D, Kong X, Li MY, Que GH (2009) Study on a water-soluble catalyst for slurry-phase hydrocracking of an atmospheric residue. Energy Fuels 23:958-961

16. Liu D, Li MY, Deng WA, Que GH (2010) Reactivity and composition of dispersed Ni catalyst for slurry-phase residue hydrocracking. Energy Fuels 24:1958-1962

17. Jeon SG, Na JG, Ko CH, Lee KB, Rho NS, Park SB (2011) A new approach for preparation of oil-soluble bimetallic dispersed catalyst from layered ammonium nickel molybdate. Mater Sci Eng B 176:606-610

18. Jeon SG, Na JG, Ko CH, Yi KB, Rho NS, Park SB (2011) Preparation and application of an oil-soluble CoMo bimetallic catalyst for the hydrocracking of oil sands bitumen. Energy Fuels 25:4256-4260

19. Zhang SY, Deng WA, Luo H, Liu D, Que GH (2008) Slurryphase residue hydrocracking with dispersed nickel catalyst. Energy Fuels 22:3583-3586

20. Liu D, Guo AJ, Ma KJ, Que GH (2006) Investigation on dispersed catalyst for slurry bed hydroprocessing of heavy oil. China Pet Process Petrochem Technol 4:55-59

21. Chen HH, Montgomery DS, Strausz OP, George ZM (1989) Hydrocracking of Athabasca bitumen using oil-soluble organometallic catalysts. Stud Surf Sci Catal 53:439-450 
22. Herbstman S (1977) Hydrotreating heavy residual oils. US Patent $4,125,455$

23. Bearden JR, Aldridge CL (1986) Catalysts and hydroconversion processes utilizing the same. US Patent 4,579,838

24. Galarraga CE, Pereira-Almao P (2010) Hydrocracking of Athabasca bitumen using submicronic multimetallic catalysts at near in-reservoir conditions. Energy Fuels 24:2383-2389

25. Ortiz-Moreno H, Ramírez J, Cuevas R, Marroquín G, Ancheyta J (2012) Heavy oil upgrading at moderate pressure using dispersed catalysts: effects of temperature, pressure and catalytic precursor. Fuel 100:186-192

26. Domokos L, Jongkind H, Rigutto MS, Van De Voort EHC, Stork WHJ (2006) Hydrocracking catalyst composition. US Patent $0,207,917$

27. Zhu YQ, Zhou DL (2011) Study on unsupported nano-MoS catalyst for clean fuel. Adv Mater Res 287-290:1860-1865

28. Ancheyta J, Rana MS, Furimsky E (2005) Hydroprocessing of heavy petroleum feeds: tutorial. Catal Today 109:3-15

29. Todorova T, Alexiev V, Weber T (2012) Energetics and electronic properties of defects at the (100) $\mathrm{MoS}_{2}$ surface studied by the perturbed cluster method. React Kinet Mech Cat 105:113-133
30. Zhang SY, Deng WA, Luo H, Liu D, Que GH (2009) Mechanism of slurry phase hydrocracking residue reaction. Acta Petrol Sin (Petrol Process) 25(2):145-149

31. Topsфe H, Clausen BS, Massoth FE (1996) Hydrotreating catalysis. Catal Sci Technol 1:11-269

32. Topsфe H, Clausen BS (1986) Active sites and support effects in hydrodesulfurization catalysts. Appl Catal 25:273-293

33. Cavitt SB (1971) Process for hydrocarbon soluble metal salts. US Patent 3,595,891

34. Rueda N, Bacaud R, Labteri P, Vrinat M (2001) Factorial design for the evaluation of dispersed molybdenum sulfide catalysts. Appl Catal A Gen 215:81-89

35. Furimsky E (2007) Catalysts for upgrading heavy petroleum feedstock. Elsevier, Singapore

36. Liang WJ, Que GH (2008) Petroleum chemistry. Petroleum University Press, Dong Ying

37. Kaernbach W, Kisielow W, Warzecha L, Miga K, Klecan R (1990) Influence of petroleum nitrogen compounds on hydrodesulphurization. Fuel 69:221-224

38. Rezaei H, Smith KJ (2013) Catalyst deactivation in slurry-phase residue hydroconversion. Energy Fuels 27:6087-6097 